\title{
Mathematics in Kenya
}

\author{
Tom Denton
}

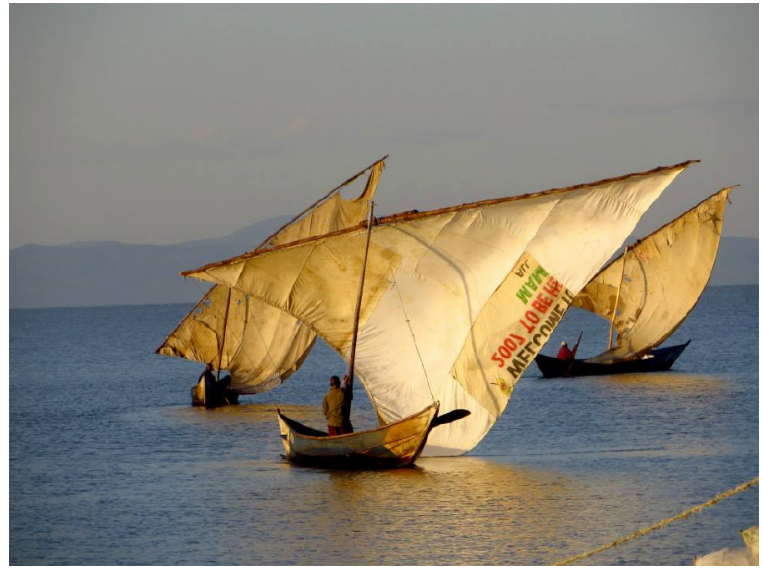

Fishermen on Lake Victoria.

I became involved in math education and research in Kenya in 2010 during the last year of my PhD. I was interested in doing some work in a developing country, and Kenya had the advantage of being both English-speaking and the place where my girlfriend at the time was setting up her own $\mathrm{PhD}$ research. So I wrote about fifty emails to people who looked like they might be interesting to talk to from all over the Kenyan university system.

Exactly one person responded, and two months later I embarked on my first trip to western Kenya. My contact was Dr. David Stern, a UK citizen who had grown up in Niger (his father, Dr. Roger Stern, is a well-known statistician working on climate

Tom Denton was a math researcher and educator, working as a postdoctoral researcher at York University. He is now employed by Google. His email address is sdenton4@ gmai1.com.

Unless otherwise credited, all photos are the property of Tom Denton.

DOI: http://dx.doi.org/10.1090/noti1266 issues), did a $\mathrm{PhD}$ in topology at the University of Warwick, and then took a post at Maseno University in Nyanza Province, where he had been for the last five years. He had a coterie of successful graduate students, all with a passion for math education.

I first travelled to Kenya for two weeks in November 2010. During that first trip, I worked alongside a British $\mathrm{PhD}$ student and a South African professor. We helped Kenyan graduate students grapple with their research topics and gave some workshops on our own research interests. (Mine, I believe, was on crystal bases.) Six months later I went back to Kenya for the first Maseno Maths Camp. Six months after that, I submitted an application for a Fulbright Scholarship from the US State Department, which I was awarded in 2012.

Mostly this is the story of the year I spent in Maseno from 2012 to 2013, what I saw of mathematics in Kenya, and the projects I worked on directly. My host during that time was Dr. David Stern, the mathematician I initially contacted in 2011. David is a man of sweeping vision who watches TED talks in his spare time and, if there's a bit of justice in the world, will give a couple himself in due time. It takes a certain kind of passion to completely jump outside all the known career paths for a Western mathematician to take a job in Nyanza Province, so far even from Nairobi. And it requires dedication to stick with it for half a decade in the face of abysmal pay, difficult working conditions, and incessant car trouble.

In exchange for all this hardship, though, there's massive opportunity for impact. There are problems to be addressed at every turn and an incredible number of opportunities to try things out and see what works. During my year in Kenya, I taught undergraduates, both face-to-face and in an online course; mentored graduate students; taught graduate workshops; cofounded a hacker 
space; ran teacher trainings; and coordinated maths camps for secondary schools. Some things worked amazingly well, and others, like the teacher trainings and a regular seminar on representation theory, failed miserably. This is the one place I've seen in academia where the ethos of "launch and pivot" was most in evidence.

You can have a hundred conversations in Kenya and almost all of them will contain the phrase "You see, the problem is...," and the problem will never be the same. Mathematics is the language of problem solving: my work in Africa was an effort to help people find the tools to define their problems and to build their own innovative solutions.

\section{Maths Camps}

The idea of offering a "maths camp" for secondary school students and their teachers came from Zach Mbasu, one of David's graduate students, following a successful effort to get statistics software into nearby secondary schools. As of January 2015, four maths camps have been offered at Maseno University (Kenya), two at Bahir Dar University (Ethiopia), and one in Ghana. Numerous one-day "camps" in schools all around Kenya have also taken place.

The basic model is to teach mathematical concepts in fun and engaging ways with a combination of local and international instructors, consisting of UK school teachers, Peace Corps volunteers, and whichever scientists and mathematicians we can get to put aside a couple weeks of their time. All of the instructors and coordinators get together for a week beforehand and spend an intense seven days plotting out curriculum for the five days of camp. We typically design five "courses": past subjects have included computational statistics, combinatorics, modular arithmetic, cryptography, epidemiology, mathematical card tricks, groups and symmetry, computer programming (the only subject that doesn't use computers), and more. Contentwise, we strive to design activity-based sessions which build up, one on the next, as the week progresses - the sorts of sessions you might expect in a high-quality math circle in the US. We finish the week with sessions that are more talkoriented on subjects that follow from what we've already explored while really pushing the limits and demonstrating that there's a whole world out there waiting to be explored.

One of my favorite sessions starts with a twoplayer game called Fifteen. The players take turns picking numbers between one and nine (without replacement) until either all of the numbers are exhausted or one player wins by getting a set of exactly three numbers that add up to fifteen. We start with some free play and exploration and ask students for any strategies or patterns that they've noticed. We then enumerate all of the different ways to make fifteen, usually in response to

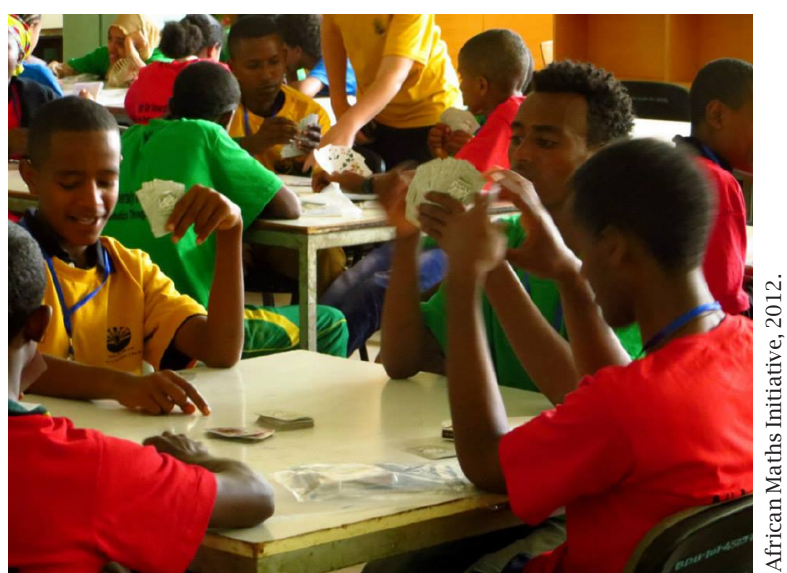

Students playing learning card games at the Maseno Maths Camp.

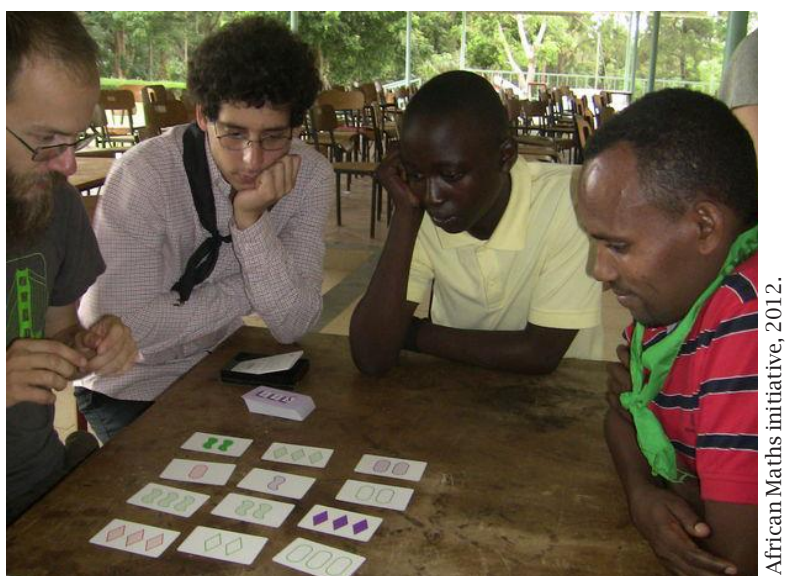

A game of Set at the Maseno Camp, with instructors from the US, UK, and Ethiopia.

a question of whether any numbers are "better" than others. A bit more guidance leads to building a magic square, where the rows, columns, and diagonals all sum to fifteen. Playing Fifteen on the magic square is exactly the same as playing tic-tactoe: we reduce a hard computational problem to a completely trivial game of three-in-a-row. Depending on time, we might then find all of the magic squares (since each student comes up with their own arrangement) and explore the symmetries of a square along the way. A counting argument and a Cayley graph provide an easy check that we've not left anything out.

We use quite a few card games in the maths camps. The rules of games are analogous to mathematical axioms: though the rules are arbitrary, we try to find rulesets which provide us with interesting play and follow them precisely once chosen. Playing a few different variants of, say, Rummy shows the different effects that can occur from slight changes in a set of axioms. Building strategies in a card game is similar to forming a conjecture (or, with a bit more work, proving a theorem). 


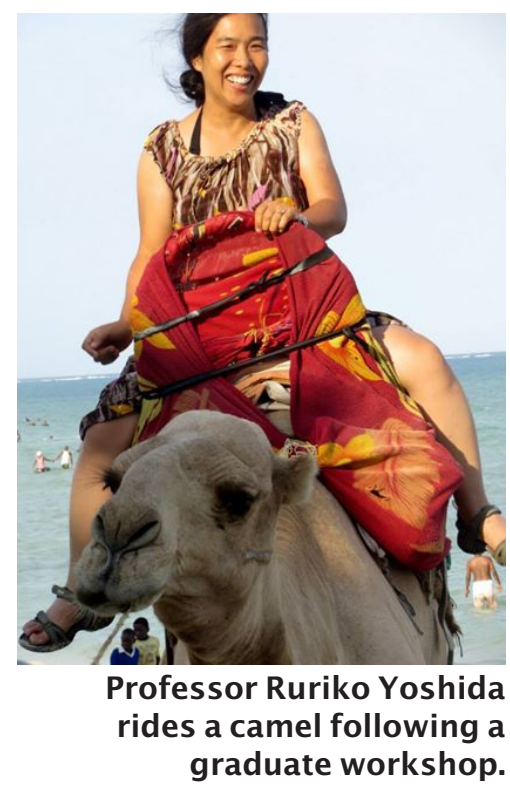

In truth, playing cards is usually forbidden in Kenyan schools, associated with gamblers and ne'er-do-wells. But many of the teachers we have worked with have decided to stop confiscating playing cards, as they are so rich in mathematical possibilities.

Our goal with the maths camps is to introduce secondary students to the beauty of mathematics and give them some experience with working with mathematical concepts. Both the primary and secondary school systems in Kenya are directed at the national exams, with their overwrought curriculum. Teaching focuses on how to get the answers to test questions without any reflection on why the methods of solution work or, in the worst cases, what the questions are even asking. We want to leave students with a sense of the importance and relevance of mathematics, alongside a sense of personal enjoyment of the subject.

We teach all of the students a theme song that I wrote for the second Maseno camp. The refrain goes:

You can't get away from mathematics, and once you've been to maths camp you wouldn't want to try.

Coz there's a beauty in the order that surrounds us, invisible until you find the rules of how and why.

The camps have been quite successful. We regularly hear from teachers about students excelling in their school math classes after coming back from the maths camp. Our ideal student is someone who isn't necessarily already interested in math, but who is gregarious and curious and likely to go home and spread the ideas from maths camp to their friends. We send students home with DVDs of free and open source math software (like Geogebra), which often find their way into schools' computer labs. In one case, a school actually secured funding to create a computer lab in response to a student who showed up with one of our DVDs.

Small measures like these help increase our impact. We can only work with a tiny fraction of the 400,000 students who graduate each year, so we strive to create as many second-order effects as we can. To that end, we also invite school teachers to attend the camp. I've found teacher training in
Kenya to be generally ineffective, largely because teachers often don't believe that alternative methods can be effective. The camps give us a way to show teachers directly what activity-based sessions can do for students.

\section{Undergraduates and Online Homework}

The required mathematics classes at Maseno University generally have between three hundred and six hundred students, with no teaching assistants. Each professor also generally has a full teaching load of four classes, possibly with some extra teaching on the side to supplement his or her income. It should come as no surprise, then, that there is almost no evaluation. A midterm and a final are offered, and the midterm generally hasn't been graded by the time the final is given. Classrooms are either grossly overcrowded or so cavernous that the board can't be seen by most of the class. And so on.

One of the more successful simple measures I discovered to deal with some of these issues was to integrate online homework systems (specifically, WebWork) into existing classes. I personally helped get WebWork into a calculus class with four hundred students and a linear algebra class with six hundred students, and helped Mary Achieng, lecturer at Strathmore University, use WebWork with four of her classes.

Online homework systems have their shortcomings, of course-it's difficult to go beyond rote learning-but the benefits in this context were substantial. The obvious benefit is that computer grading allows students to get instantaneous feedback on whether they've found a correct answer or not. Every student gets different numbers in their problem set, so one can't directly copy the work of another student. Giving five chances to complete each problem also provides space for getting a problem wrong and learning from mistakes and reduces the incentives for cheating.

These are the standard benefits of WebWork. In my classes in the US and Canada, I've found a combination of WebWork (for drills) and written homework (for proofs and concepts) to be immensely effective. The combination emphasizes the need to know how to work carefully towards a correct answer and the separate need to understand the how and why of a line of reasoning. Unfortunately, there is little opportunity for grading written work when working with students at the scale of these Kenyan classes.

There are two added benefits to WebWork in Kenya, however. We found many undergraduates were under the impression that computers were for computer science students. WebWork forced these students to interact with computers on a weekly basis, building basic computer literacy while also demonstrating that there's a relationship between mathematics and computation. More 
concretely, weekly time in the computer lab gave students the chance to augment their lectures with videos from the Khan Academy and articles from Wikipedia, which they never would have engaged with otherwise.

All of that said, there are at least two large hurdles to using WebWork at scale in Kenya. The first is the difficulty of getting support for lecturers to use the system: widespread adoption would require funding for training and on-site support. The second is that WebWork could use some serious work on the user interface side. For example, the process for creating new problems involves writing in specialized Perl libraries, which is a lot to ask of math lecturers in Kenya. Overall, however, WebWork is a fantastic tool and, taken up on a large scale with the right level of support, would have a good chance to vastly improve math education in Kenya and many other developing countries with similar problems.

Professor Gunnar Stefánsson of the University of Iceland is developing another online homework system called Tutor-Web, which has been piloted at Maseno University by lecturer Victoria Warain. Gunnar's system scales the difficulty of problems to the ability of students, using an interesting statistical evaluation of problem difficulty and interrelatedness. This raises some interesting problems for evaluation in the classroom: If student $X$ gets twenty easy problems right, while student Y gets five hard problems right, how do we assign them meaningful and useful grades? Gunnar and his graduate students have been doing some great work resolving these questions of evaluation and improving student incentives. The system is aimed at creating a richer interactive experience for the students and certainly comes with all of the added benefits of online homework systems in the Kenyan context. Gunnar's system also requires less in the way of ongoing IT support, which is a significant bonus.

The simple effectiveness and impact of the online homework systems should be briefly contrasted with some other efforts at online education I was involved with. Maseno University has an online learning program, for which I taught a section on abstract algebra. There was a clear problem of enrollment: the first run of the course had eight students, and the second (which I begged out of) had just one. Compared with the hundreds of students overwhelming the face-to-face sections, it's clear that the online components aren't meeting the needs of traditional students. I put a significant amount of effort into creating a system of online notes for the course, as well as a set of video lectures, which have mostly gone unused.

Online homework systems are a key component of a "hybrid" education model where humans and computers are each put to their best effect. Human involvement in the classroom creates a social bond

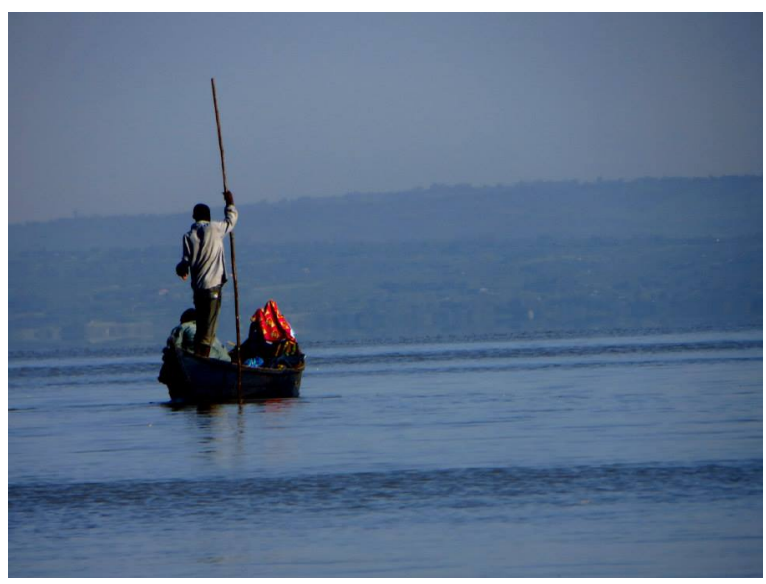

Fishermen on Lake Victoria.

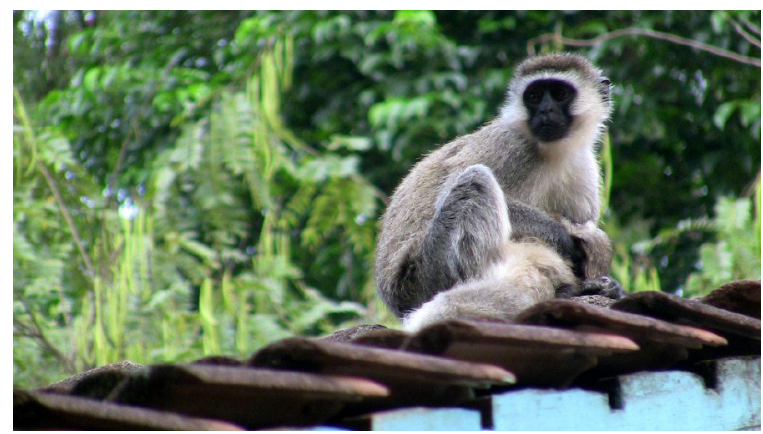

Vervet monkey on our roof in Maseno.

with the class, a sense of ongoing obligation, while also providing a forum for interactive conversation about the material that is often lacking in MOOCs. Within the Kenyan context, where uptake of technology and the Internet is still quite low and emphasis on traditional credentials is high, a full move to online education is unnatural for students and lecturers. Online homework systems provide a way to create more technologically savvy students without leaving them overwhelmed or lost, improving without abandoning the existing educational system.

\section{Graduate Students and Research}

I am not quite sure how to describe the state of Kenyan postgraduate work without sounding overly dismal or insulting to people who are trying their best in difficult circumstances. Suffice to say that the Kenyan mathematical community has been almost entirely isolated for much of the last thirty years. Former President Daniel Arap Moi (1978-2002) can probably take some of the blame for this directly. Moi was a man with a sixth-grade education, famously unconvinced of the benefits of higher education. The minimal state funding for the universities led to a scramble to enroll as many students as possible, with results that the American audience should be mindful of. Teaching overcrowded classes became the main work of the university, leaving little time for research and conferences. 


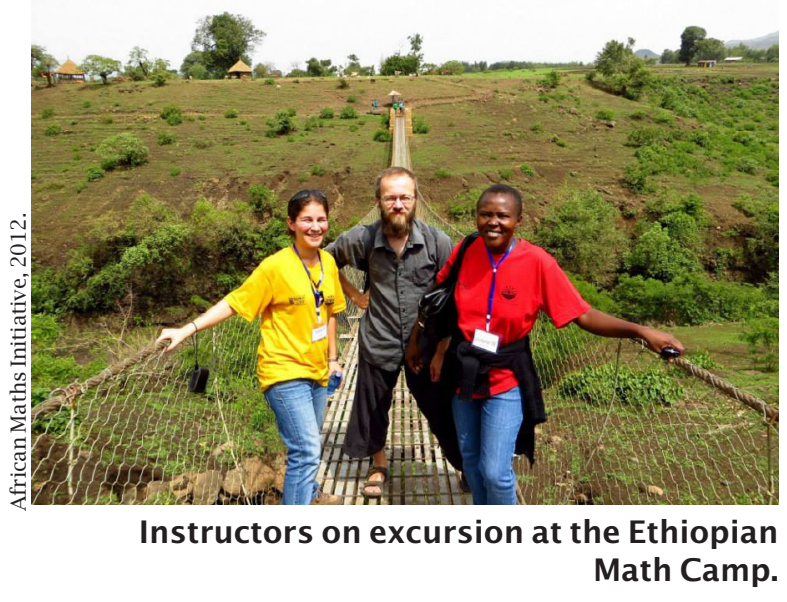

One of the most heartening efforts I've seen, though, is a cluster of young researchers from the University of Nairobi who have decided to collectively pursue algebraic geometry abroad, with the intention of coming back to Nairobi and having a functioning research group. (One of their number, Jared Ongaro, is notable also for cofounding the Kenyan Math Olympiad, another excellent effort to break the isolation.) In July 2013 this group, led by Professor Patrick Weke and Dr. James Katende, organized a three-week workshop on applicable algebraic geometry which went above and beyond any of my expectations for such a workshop. Professor Balazs Szendroi of Oxford (who has been involved in Kenya for some years) assembled a team of seven international lecturers, and Professor Gavin Brown headed the scientific coordination. The topics ranged from introductory linear algebra and commutative algebra in the first week to Dr. Ruriko Yoshida's introduction to algebraic statistics in the third week.

What set this workshop apart was the core of focused participants from the University of Nairobi, who came with some prior affection for the subject matter, led the charge during our interactive problem sessions, and worked with other participants on problem sets late into every evening. Local initiative makes all the difference.

On another front, Strathmore University has started an East African Mathematics Conference, now in its fourth year. Because the research community is relatively small, the conference has a broad focus. It begins with workshops in pure and applied mathematics, math education, and research methods, and then has a few days of presentations from invited speakers. With an audience coming in from across Africa and a sizable European contingent, the conference is an excellent step towards bringing Kenya into the international math community.

Finally, the African Institute of Mathematical Sciences (AIMS) is doing a fantastic job of building bridges. While there's no branch yet in Kenya,
I have met numerous people who have benefitted from time at AIMS centers. I also had the opportunity to teach at AIMS in South Africa in January 2013, alongside Dr. David Stern, and to see their model firsthand. AIMS brings in lecturers from around the world to lead three-week sessions with the best African graduate students in math and physics. Behind the scenes AIMS is engaging their host countries to pay half of the costs of running each center, creating a precedent for serious government funding of science and research. In time, the stream of students going back to their home countries will build a critical mass of researchers and educators, and African mathematics will flourish in its own right.

\section{Hackerspaces}

A variety of technology hubs have popped up across Africa in the last few years. They serve a number of roles, providing space for skill-sharing and coworking, business incubation, hackathons, unconferences, barcamps, and more. The most famous is the iHub in Nairobi, which acts as the de facto heart of the Kenyan technology community. I've met dozens of fascinating people in my visits to iHub. It was also where I first saw and tried Google Glass.

In early 2013 I attended TEDx: Kisumu. Kisumu is Kenya's third largest city and the city closest to Maseno (a bit less than an hour's drive depending on the rain and the roadblocks). We had heard somewhat randomly of the event and had only a faint idea of the tech community in Kisumu at the time. The event was a live screening of another TED event going on in Hawaii, focused on disruptive innovation. At the end of the night, as the bunch of strangers milled about uncomfortably, a couple of the coordinators rounded everyone up into a circle and forced us into conversation.

The coordinators, Herbet Kisara, Simeon Obwego, James Odede, and Evan Green-Lowe, were mostly working with international non-governmental organizations (NGOs) but interested in jumpstarting a tech community in Kisumu. They had been kicking around the name "LakeHub" in their own conversations, and by the end of the night the group had resolved to host LakeHub's first event. A month later we hosted a design-thinking workshop in a Kisumu hotel.

Design-thinking is an attempt at formalizing the process of innovation, starting with identifying problems to engage with, followed by solution brainstorming, narrowing of ideas, revisiting the initial problem, and building and iterating on prototypes. Our workshop was focused on building a better wallet, with an initial turnout of about thirty people.

Following that event, we secured a space at a local coffee house for weekly presentations and skill-sharing. I gave presentations on proper 
password storage (salted hashes), programming in Python, and game design, while others gave bare-knuckle intros to app development for Android phones, tutorials on building websites for businesses, and Arduino programming. Recently, LakeHub moved into its own permanent space in Kisumu and continues hosting regular events. They have had funding from Google for a high school outreach program, CS4HS, and ongoing involvement with Maseno University's CS program and the growing tech community in Nairobi.

LakeHub's core constituency is a diverse mix of people, including students and people who took a CS degree but for one reason or another didn't move to Nairobi. The community also includes business people with an interest in technology and Kisumu's few tech freelancers, a network of people who, prior to LakeHub, were there but mostly unconnected. It is, to the best of my knowledge, the first stable tech hub in Africa outside a capital city. This is vital; some 80 percent of Kenya's population is rural, which means that Kenya's problems are mainly rural problems. In the long run I'm hopeful that LakeHub will provide a place for Kisumu's tech community to start tackling some of these rural problems.

\section{Epilogue}

When you start working in the developing world, you start seeing a lot of abandoned wells. Watercarrying is easy to identify as a problem with a fairly simple technical solution: build a better pump. The proposal gets written, the pilot goes well, and a couple of years later hundreds of pumps of a certain design start popping up in rural villages, funded by large non-governmental organizations (NGOs) and installed by smaller NGOs. After a while, a flaw becomes apparent in the design, but with no local factories to supply spare parts, poor transportation networks pushing up the price of nonlocal parts, and the end of the original grant passing by, the well falls into disrepair and disuse. The NGOs involved may not even be aware of the problems if they don't have a longterm presence in the hundreds of villages in which they've installed the pumps. (While presented here as a parable, you can Google the PlayPump to see a real-world example.)

I aim in my work to avoid building abandoned wells, which means trying to work around some classic root problems mainly having to do with the disconnect between the NGOs and the local communities. Transient NGOs often misidentify problems in a local community or else come up with solutions that can't possibly work in the local context. By teaching essential problem-solving skills, including fundamental math and statistics, we give people the tools to better understand the world around them and build sustainable solutions to the problems they identify in their communities.

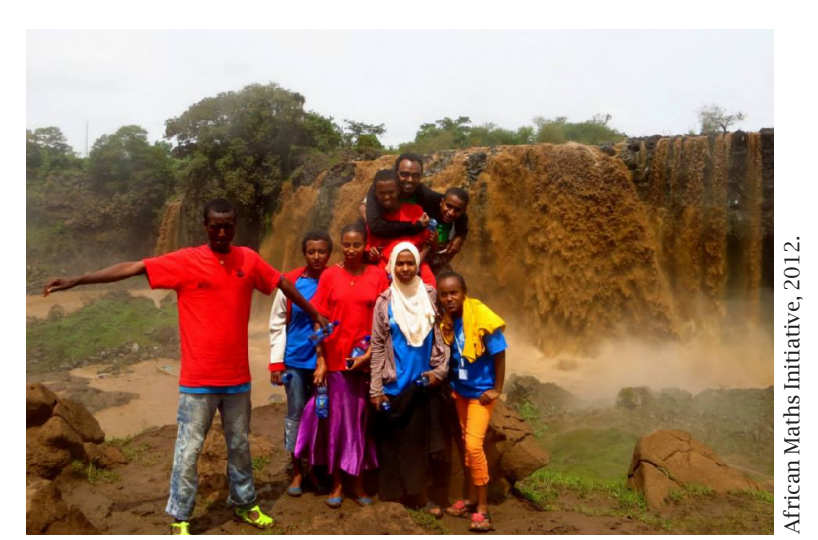

Ethiopian Maths Camp students at the source of the Blue Nile.

Computer science increasingly gives a path from understanding to a low-cost solution, whether through websites for undeservedly obscure tourist destinations, GPS tracking on fishing boats, farm-to-market apps, or customer databases for predicting demand for goods. I aim to give people the tools to understand and to build, to innovate and to iterate.

After returning to Canada I had one year left of a postdoctoral placement, meaning I was immediately starting a job search. After a great deal of soulsearching, I decided to take leave of academia for a while and took a job with Google. My reasons were many but included a sense that the job and tenure process is focused on impact factor at the expense of actual impact. I came through the job process with the feeling that the "later, later" of career-building leaves many kinds of important work-like outreach or building better software-by the wayside. My work in Africa seemed to be seen primarily as a lower publication count. With Google I am working at global scale, drawing heavily on my background in mathematics while dealing with the limitations of applications. I am picking up skills that will be useful in future work in Africa while making enough of a salary to fund other initiatives I really believe in. Google's extensive outreach efforts in the developing world also provide opportunities to stay involved with the projects I have outlined above.

If you're interested in doing this kind of work, I highly recommend getting in touch with AIMS or the African Maths Initiative, the organization we founded to run the maths camps. There are also very few Fulbright applications in mathematics for sub-Saharan Africa, and the international interest in building STEM capacity gives these applications extra weight. 